\title{
microRNAs and thyroid cancer: Biological and clinical significance (Review)
}

\author{
GIULIA COSTANZA LEONARDI ${ }^{1}$, SAVERIO CANDIDO ${ }^{1}$, MAURIZIO CARBONE ${ }^{2}$, \\ VALERIA COLAIANNI ${ }^{2}$, SEBASTIANO F. GAROZZO ${ }^{2}$, DIANA CINÀ ${ }^{2}$ and MASSIMO LIBRA ${ }^{1}$ \\ ${ }^{1}$ Laboratory of Translational Oncology and Functional Genomics, Section of Pathology and Oncology, \\ Department of Biomedical Sciences, University of Catania; ${ }^{2}$ Clinical Pathology Laboratory, Garibaldi Hospital, Catania, Italy
}

Received April 27, 2012; Accepted May 21, 2012

DOI: $10.3892 /$ ijmm.2012.1089

\begin{abstract}
Despite recent advances in the management of thyroid cancer, the survival rate of this tumor may still be improved. Therefore, the identification of biological and molecular features of indolent and aggressive disease would be critical to define clinically useful predictors of high-risk lesions. microRNAs (miRNAs) are small RNA molecules with regulatory function and marked tissue specificity that modulate multiple targets belonging to several pathways. They are frequently deregulated in cancer and constitute a new class of blood-based biomarkers useful for cancer detection and prognosis definition, including thyroid cancer. In this review, the role of miRNAs in thyroid cancer development is described. The most common miRNAs detected in thyroid cancer along with their clinical significance are also discussed. Further studies aimed to detect plasma-based miRNA biomarkers in thyroid cancer patients may provide further insight into the management of thyroid cancer.
\end{abstract}

\section{Contents}

1. Introduction

2. Mechanism of action and functions of microRNAs

3. microRNAs and cancer

4. microRNAs and thyroid carcinoma

5. Conclusion

\section{Introduction}

Gene expression in normal cells is highly regulated by complex gene regulatory networks. Disruption of these networks may

Correspondence to: Dr Massimo Libra, Laboratory of Translational Oncology and Functional Genomics, Section of Pathology and Oncology, Department of Biomedical Sciences, University of Catania, Via Androne 83, I-95124 Catania, Italy

E-mail: mlibra@unict.it

Key words: thyroid cancer, microRNA, biomarkers lead to cancer. Previous studies have shown the presence of small regulatory RNAs, known as microRNAs (miRNAs), that represent a class of highly conserved small endogenous RNAs made up of 20-22 nucleotides single-stranded noncoding proteins. These miRNAs are involved in the regulation of proliferation differentiation and apoptosis by interfering with protein expression (1-3), usually resulting in translational repression or target degradation and gene silencing (4). Accumulating evidence has shown that miRNAs are associated with cancer because of their deregulation (5-7). Many miRNAs are expressed in a tissue-specific manner and exhibit expression profiles that are different between normal and neoplastic tissues and between tumors with distinct biological properties $(8,9)$. Several research lines have been developed to understand the role of miRNAs in cancer development and in clinical practice, as tumor biomarkers and therapeutic targets. The deregulated expression of miRNAs has been recognized in multiple cancer types, including thyroid cancer. Thyroid cancer represents an attractive model for studying the events involved in epithelial cell multistep carcinogenesis as these events comprise a broad spectrum of lesions with different degrees of malignancy. Most thyroid carcinomas originate from thyroid follicular cells and are subdivided into well-differentiated papillary thyroid carcinoma (PTC) and follicular thyroid carcinoma (FTC). Both PTCs and FTCs may progress into poorly differentiated carcinoma or may completely lose differentiation to give rise to anaplastic carcinoma (ATC). Less than $5 \%$ of cells within the thyroid gland are C-cells that give rise to medullary thyroid carcinoma (MTC) (10). The aim of this review was to highlight the latest findings on miRNA expression profiles in various subtypes of thyroid cancer.

\section{Mechanism of action and functions of microRNAs}

The miRNAs that were first discovered, lin-4 $(11,12)$ and let-7 $(13,14)$ were identified genetically in Caenorhabditis elegans. Subsequently, hundreds of non-protein-coding miRNAs were identified across species, showing that they are highly conserved (2,15-17). Both cloning and bioinformatic approaches have shown that the human genome contains a larger number of miRNAs than previously appreciated (18). It has been suggested that the total number may be $>800$ or 1,000 (3). miRNA genes located in the introns and/or exons 


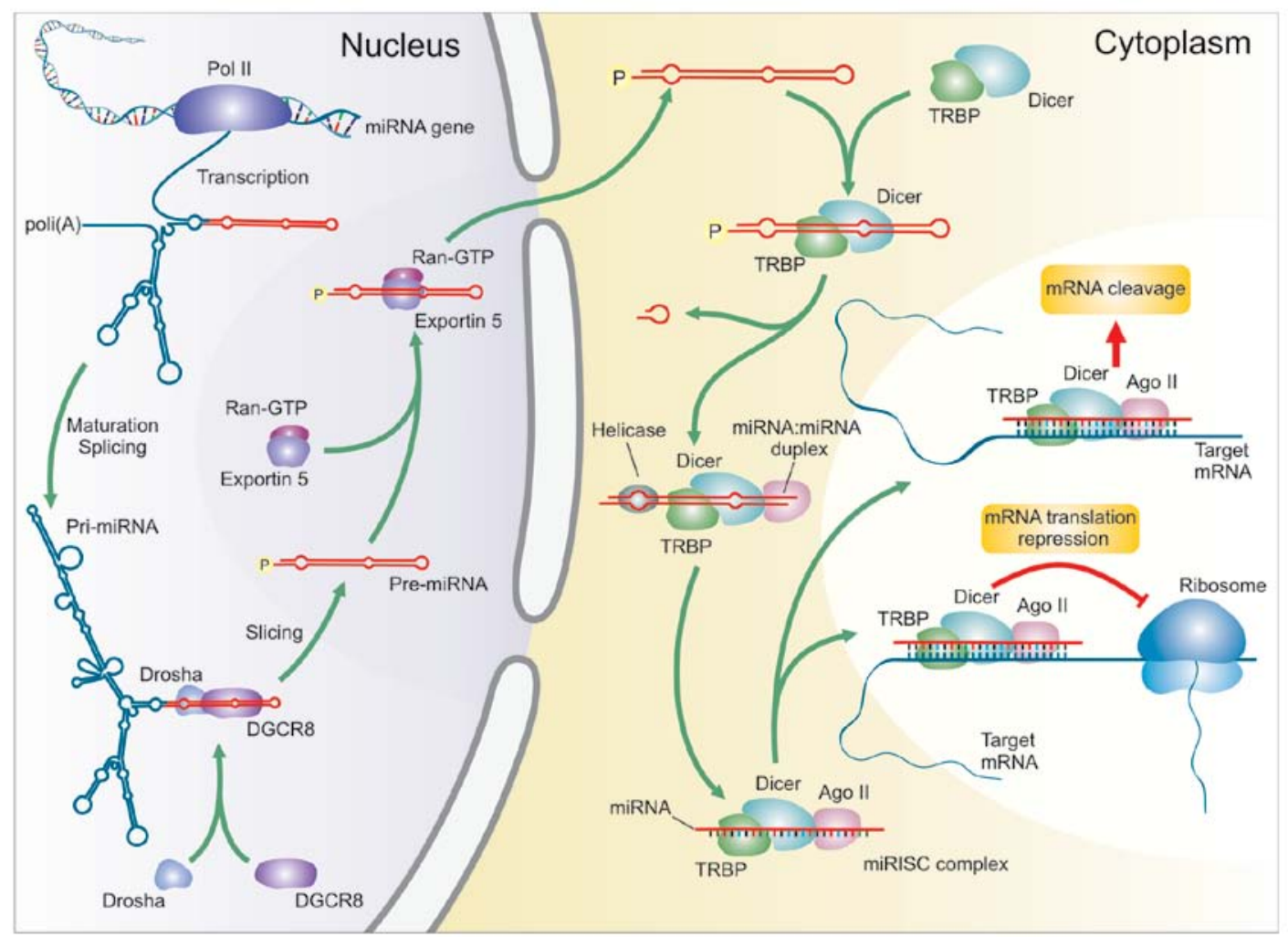

Figure 1. Mechanism of action and function of microRNAs.

of protein-coding genes or in the intergenic regions between protein-coding genes, may form polycistronic clusters or exist individually $(16,19,20)$. miRNA biogenesis consists of a stepwise-process that starts with a primary transcript RNA (pri-miRNA) transcribed from a miRNA gene by RNA polymerase II and thus processed into a stem-loop structure of 70-100 nt [precursor miRNA (pre-miRNA)] by a doublestrand (ds)-RNA-specific ribonuclease, Drosha, with the help of its binding partner DGCR8 (21-23). These pre-miRNAs are transported into the cytoplasm via an exportin-5-RanGTP dependent mechanism (24-26). In the cytoplasm, they are digested by a second, dsRNA-specific ribonuclease known as Dicer, with the help of transactivating response RNA-binding protein (TRBP) and argonaute 2 AGO2 (27-29). The released 17-25 nt mature miRNA is bound by a complex termed miRNAassociated RNA-induced silencing complex (miRISC) (30). miRNAs can direct the RISC to downregulate gene expression by using one of 2 post-transcriptional mechanisms: mRNA cleavage or translational repression (Fig. 1). According to the prevailing model, the selection of post-transcriptional mechanisms is determined by the identity of the target. Once incorporated into a cytoplasmic RISC, the miRNA will specify cleavage if the mRNA has sufficient complementarity to the miRNA or it will repress productive translation if the mRNA does not have sufficient complementarity to be cleaved but has a suitable constellation of miRNA complementary sites $(31,32)$. A single miRNA can regulate multiple target genes, while a single gene can be targeted by multiple miRNAs, suggesting that the miRNAome and mRNAome interaction is a complicated network (20). This enormous variability suggests that miRNAs may be involved in almost all physiological processes of the cell, defining a regulatory control of approximately $1 / 3$ of the messenger RNA of the whole human genome (33).

\section{3. microRNAs and cancer}

Cell proliferation, differentiation and apoptosis are essential processes in cell and tissue homeostasis and their alteration is a fundamental step in the initiation and progression of malignant disease. Evidence has shown that miRNA mutations or misexpression correlate with various human cancers, indicating that miRNAs function as tumor suppressors and oncogenes (33). Genome-wide studies have demonstrated that miRNA genes are frequently located at cancer-associated genomic regions or in fragile sites. They are also present in the minimal regions of loss of heterozygosity, in the minimal regions of amplifications or in the common breakpoint regions, suggesting that miRNAs may be a new class of genes involved in human tumorigenesis (34). Analysis of miRNA expression profiles in tumor samples and normal tissues have displayed different patterns of overexpression or downregulation (8). A general finding is that global miRNA expression levels are lower in tumor tissues than normal tissues independent of cell type. In addition, poorly differentiated tumors present a lower global level of miRNA expression compared to more differentiated tumors. These data are consistent with the hypothesis that high global miRNA expression levels are associated with cellular differentiation (35).

Previously, a series of bioinformatics prediction programs, based on mathematical algorithms, have been developed to properly identify the hypothetical mRNA targets for each specific miRNAs. Interestingly, predominant miRNA targets 
are transcription factors or kinases and researchers are currently attempting to dissect the target genes of miRNAs and their signaling pathways involved in cancer (36). The deregulation of miRNAs participates in the activation of cell proliferation or in the inactivation of the apoptotic signaling pathway in conjunction with other genetic changes leading to cancer pathogenesis (37). Several miRNA signaling pathways have been carefully studied: i) the human RAS gene contains multiple let-7 complimentary binding sites, allowing the let-7 miRNA family to regulate RAS expression (38); ii) miR-19 has been demonstrated to bind the 3' UTR of phosphatase and tensin homologue (PTEN) mRNA in vitro suggesting that overexpression of mir-19 in tumor cells could be an alternative mechanism by which the PI3K/Akt signaling pathway is activated (39); iii) the mir-17-92 cluster is overexpressed in multiple malignancies and, in a mouse B-cell lymphoma model, it has been demonstrated to act with c-myc expression to accelerate tumor development (40); iv) miRNAs also interfere with the apoptotic process by blocking the expression of critical apoptosis-related genes $(8,41-43)$; v) KIT is an important tyrosine kinase receptor in cell differentiation and growth. Inhibiting the KIT signaling via miRNAs may contribute to uncontrolled cell growth in certain type of cells (44); vi) miR-106a and miR-20a may negatively regulate retinoblastoma 1 (RB1) and transform growth factor (TGF)- $\beta$ signaling (45); g) miR-372 and miR-373 are potential oncogenes by numbing the p53 pathway and allowing tumorigenic growth in the presence of wild-type p53 (46).

Moreover, the scientific community is focusing on miRNAexpression signatures that may represent a powerful tool for cancer diagnosis, for defining a treatment strategy for patients, for prediction of the prognosis and for monitoring treatment response (33).

\section{4. microRNAs and thyroid carcinoma}

A number of studies have analyzed miRNA expression in different types of thyroid tumor, demonstrating that miRNA deregulation occurs in cancer tissues compared to their normal counterparts. Moreover, miRNA expression profiles presented high variability among the different histotypes of thyroid cancer (Table I).

Follicular thyroid carcinoma. FTC belongs to the welldifferentiated thyroid carcinoma group with a usually more aggressive behavior than PTC. Several studies have attempted to define the roles of miRNA deregulation in this histotype.

In 2006, Weber et al (47) published data on deregulated miRNA expression in FTC. It was investigated whether miRNAs were differentially expressed in human FTC and follicular adenomas (FAs) using 2 high-density expression arrays to identify miRNAs and their target genes. In total, 45 primary thyroid samples (23 FTC, 20 FA and 4 normal control thyroid samples) were analyzed. Four miRNAs (miR-192, miR-197, miR-328 and miR-346) were observed to be overexpressed in FTCs compared to FA. These miRNAs appeared to be specific to the FTC phenotype. miR-197 and miR-346 were also validated by real-time quantitative RT-PCR that confirmed their overexpression. The effects of these 2 miRNAs have been functionally studied using two cell lines of human thyroid cancer, FTC133 and K5, a cell line of human papillary thyroid cancer, NPA87, and a line of human embryonic kidney cells, HEK293T as the control. The induced overexpression of miR-197 and miR-346 stimulated cell proliferation in vitro, while the downregulation of miR-197 and miR-346 led to cell growth suppression in both the FTC133 and K5 cell lines, but not in the NPA87 cell line, confirming that the deregulation of miR-197 and miR-346 contributes to FTC carcinogenesis, but not PTC carcinogenesis. The targets of these 2 miRNAs were also detected. EFEMP2 (fibulin 4), a protein involved in the stabilization and organization of extracellular matrix structures that functions as as tumor suppressor $(48,49)$, was inhibited by the overexpression of miR-346. The activin A receptor type 1 (ACVR1), a potent inhibitor of cell growth in several human cells types, including the thyroid epithelium (50), and tetraspanin 3 (TSPAN3), whose exact biological role in tumors is still unknown, were both downregulated as a consequence of the overexpression of miR-197. The authors suggested that these 2 miRNAs may participate in the malignant transformation of follicular tumors and that their target genes may provide new molecular markers for distinguishing malignant from benign FTC (FA).

Nikiforova et al (51) did not confirm the results published by Weber et al, except for miR-197. miRNA expression levels were detected in 60 surgically removed thyroid neoplastic and non-neoplastic samples and in 62 fine-needle aspiration (FNA) samples by RT-PCR using the TaqMan miRNA panel or individual miRNA sequence-specific primers. miRNA expression levels were also calculated relative to normal thyroid tissue. Various histopathological types of thyroid tumors, including those derived from the same cell type, showed significantly different profiles of miRNA expression. Oncocytic tumors, conventional follicular tumors, papillary carcinomas and MTCs formed distinct clusters on the unsupervised hierarchical cluster analysis. A significant correlation between miRNA expression patterns and somatic mutations was observed in papillary carcinomas. A set of 7 miRNAs (miR-187, miR-221, miR-222, miR-146b, miR-155, miR-224 and miR-197) that were most differentially overexpressed in thyroid tumors vs. hyperplastic nodules in the surgical samples was validated in the FNA samples, displaying a high accuracy of thyroid cancer detection. miR-187 is one of the most upregulated miRNAs in PTC and FTC but remains unchanged in FA. The authors suggested that miR-187 may be a useful marker to discriminate FTC from FA. However, it is not suitable for discriminating FTC from other carcinomas of follicular origin.

The study by Colamaio et al (52) aimed to evaluate the expression and the role of miR-191 in thyroid carcinogenesis. The expression of miR-191 was analyzed by quantitative RT-PCR in tissue samples from patients with FA $(n=24)$, FTC $(n=24)$, PTC $(n=15)$, anaplastic thyroid carcinoma $(n=8)$, and in the follicular variant of PTC $(n=6)$ compared to the normal tissue of the thyroid gland. miR-191 was downregulated in FA, FTC and the follicular variant of PTC. They identified CDK6, a serine-threonine kinase involved in the control of cell cycle progression, as a novel target of miR-191. Moreover, the restoration of miR-191 expression in WRO cells (a follicular thyroid cell line) reduced cell growth and the migration rate on vitronectin. CDK6 overexpression, correlated with miR-191 downregulation, was established in FA and FTC, suggesting a 
Table I. miRNAs in thyroid tumors.

\begin{tabular}{|c|c|c|}
\hline $\begin{array}{l}\text { Thyroid } \\
\text { tumor type }\end{array}$ & miRNAs & Author/(Refs.) \\
\hline FTC & miR-191 & Colamaio et al (52) \\
\hline FTC & miR-192, miR-197, miR-328 and miR-346 & Weber et al (47) \\
\hline $\begin{array}{l}\text { FTC, PTC } \\
\text { other thyroid } \\
\text { variants }\end{array}$ & $\begin{array}{l}\text { PTC: miR-31, miR-122a, miR-146b, miR-155, miR-187, } \\
\text { miR-205, miR-221, miR-222 and miR-224 } \\
\text { Conventional FA: miR-190, miR-205, miR-210, miR-224, miR-328, miR-339 and miR-342 } \\
\text { Oncocytic FA: miR-31, miR-183, miR-203, miR-221, miR-224 and miR-33. } \\
\text { Conventional FTC: miR-146b, miR-155, miR-187, miR-221, miR-222 and miR-224 } \\
\text { Oncocytic FTC: miR-183, miR-187, miR-197, miR-221, miR-222 and miR-339 } \\
\text { Poorly differentiated carcinomas: miR-129, miR-146b, } \\
\text { miR-183, miR-187, miR-221, miR-222 and miR-339 } \\
\text { ATC: miR-137, miR-155, miR-187, miR-205, miR-214, miR-221, miR-222 and miR-224 } \\
\text { MTC: miR-9, miR-10a, miR-124a, miR-127, miR-129, miR-137, } \\
\text { miR-154, miR-224, miR-323 and miR-370 }\end{array}$ & Nikiforova et al (51) \\
\hline PTC & miR-21, miR-146, miR-181, miR-221, miR-222 & He et al (59) \\
\hline PTC & $\begin{array}{l}\text { miR-15a, miR-34a, miR-34c, miR-96, miR-99a, miR-100, miR-107, miR-125b, } \\
\text { miR-127, miR-128b, miR-130b, miR-135b, miR-139, miR-141, miR-142-3p, miR-145, } \\
\text { miR-146, miR-148, miR-149, miR-154, miR-181a, miR-185, miR-200a, miR-200b, miR-211, } \\
\text { miR-213, miR-216, let7d, miR-218, miR-299, miR-302b, miR-302c, miR-323 and miR-370 }\end{array}$ & Cahill et al (60) \\
\hline PTC & left-7b & Ricarte-Filho et al (6 \\
\hline PTC & miR-181b, miR213, miR 220, miR-221 and miR-222 & Pallante et al (62) \\
\hline PTC & $\begin{array}{l}\text { miR-19b-1,2, miR-21, miR-30a-5p, miR-30c miR-31, miR-34a, miR-130b, miR-145sh, } \\
\text { miR-172, miR-181a, miR-181b, miR-213, miR-218, miR-221, miR-222, miR-223, } \\
\text { mir-224, miR-292-as, miR-300 and miR-345 }\end{array}$ & Tetzlaff et al (64) \\
\hline PTC & miR-146b, miR-221 and miR-222 & Chen et al (65) \\
\hline PTC & miR-21, miR-146b, miR-181b, miR-213, miR-220, miR-221 and miR-222 & Sheu et al (66-68) \\
\hline PTC & miR-146b, miR-221 and miR-222 & Chou et al (69) \\
\hline PTC & miR-221 and miR-222 & Visone et al (70) \\
\hline ATC & miR-17-3p, miR-17-5p, miR-18a, miR-19a, miR-19b, miR-20a and miR-92-1 & Takakura et al (73) \\
\hline ATC & miR-21, miR-26a, miR-138, miR-146b, miR-219, miR-221, miR-222 and miR-345 & Mitomo et al (76) \\
\hline ATC & miR-30 and miR-200 & Braun et al (78) \\
\hline ATC & $\operatorname{miR}-200$ & Park et al (79) \\
\hline ATC & miR-26a, miR-30a-5p, miR-30d and miR-125b & Visone et al (80) \\
\hline ATC & miR-146a & Pacifico et al (81) \\
\hline MTC & miR-19, miR-183 and miR-375 & Abraham et al (82) \\
\hline
\end{tabular}

FTC, follicular thyroid carcinoma; PTC, papillary thyroid carcinoma; ATC, anaplastic thyroid carcinoma; MTC, medullary thyroid carcinoma.

role of miR-191 downregulation (likely by targeting CDK6) in the generation of the follicular histotype of thyroid carcinoma.

Papillary thyroid carcinoma. PTC is the most common malignancy in thyroid tissue, accounting for $\sim 80 \%$ of all thyroid cancers (53). Genetically, PTC is characterized by alterations in the RET/PTC-RAS-BRAF signaling pathway $(54,55)$ through activating mutations in BRAF and RET/PTC gene rearrangements $(56,57)$. A strong inherited genetic predisposition to PTC has been suggested by case-control studies demonstrating a 3 - to 8-fold risk in first-degree relatives, one of the highest of all cancers. However, there are no identified genes predisposing or contributing to PTC. The mechanisms may require the interaction of 2 or more regulatory, rather than protein-encoding genes (58).

He et al (59) identified a set of 5 miRNAs (miR-146, miR-221, miR-222, miR-21 and miR-181) significantly overexpressed in PTC compared to normal tissue. Inter alia miR-146, miR-221 and miR-222, displayed 11- to 19-fold higher levels in PTC than in normal tissues. The expression of miR-221 was detectable in normal thyroid tissue adjacent to PTC tumors from all patients suggesting, as the authors highlighted, that 
the increased expression of miR-221 in normal thyroid tissue may be an early genetic event in PTC carcinogenesis and may play a role as an oncogene in the thyroid. The study analyzed the predicted targets of the 3 most significantly overexpressed miRNAs (-221, -222 and -146), by using publicly available algorithms, and found a group of 19 genes clustered together with miR-221 and miR-222, whose expression levels were significantly lower in PTC tumors compared to normal tissues. KIT was one of the genes displaying profound mRNA underexpression in PTC tumors. This observation did not apply to all tumors, emphasizing the complexity of these regulatory pathways, which may be organ- or cell-specific. To date, the biological significance of the loss of c-KIT in thyroid tumors is not clear. Intriguingly multiple miRNAs have been predicted to target KIT, including those overexpressed in PTC, and it is possible that the multiple interaction opportunities provided by networks or 'signatures' of miRNA deregulation create different responses in target genes under different circumstances and combinations.

Cahill et al (60) studied the effects of the RET protooncogene on gene expression and the transcriptional regulation of PTC cell lines carrying the ret/PTC1 rearrangement and the expression of miRNAs in 2 human PTC cell lines carrying the ret/PTC1 rearrangement, compared with normal thyroid cell lines. Apart from alterations on the expression profiles of the coding genes involved in cell differentiation and proliferation (CEBPB, CCNG1, IFITM3 and HTRA), they analyzed miRNA expression profiles. They found 20 miRNAs significantly overexpressed (miR-34a, miR-96, miR-99a, miR-100, miR-125b, miR-128a, miR-128b, miR-130b, miR-139, miR-141, miR-142-3p, miR-146, miR-148, miR-185, miR-200a, miR-200b, miR-211, miR-213, miR-216 and let-7d) and 15 downregulated miRNAs (miR-15a, miR-34c, miR-107, miR-127, miR-135b, miR-145, miR-149, miR-154, miR-181, miR-218, miR-299, miR-302b, miR-302C, miR-323 and miR-370) in tumor cell lines compared to normal thyroid tissues.

In 2009, Ricarte-Filho et al (61) performed a functional study to investigate the involvement of miRNA let-7f in PTC development. They showed that let-7f induction in TPC-1 cells, a human PTC cell line that spontaneously harbors the RET/ PTC1 oncogene, causes a marked reduction in cell proliferation and induced the expression of molecular markers characteristic of thyroid differentiation (TITF1) suggesting that let-7 miRNA is an essential regulator of thyroid carcinogenesis.

Pallante et al (62) also analyzed genome-wide miRNA expression profiles in human thyroid PTCs using a microarray (miRNA Chip microarray) containing hundreds of human precursor and mature miRNA oligonucleotide probes. Using this approach, they found an aberrant miRNA expression profile that clearly differentiates PTCs from normal thyroid tissues. In particular, a significant increase in miRNAs, miR-221, -222 and $-181 \mathrm{~b}$, was detected in PTCs in comparison with normal thyroid tissue. Functional studies, performed by blocking miR-221 function and by overexpressing miR-221 in human PTC-derived cell lines, suggested a critical role of miR-221 overexpression in thyroid carcinogenesis. However in 2010, Chiang et al did not confirm miR-220 as a miRNA in their detailed study on mammalian miRNA expression profiles (63).

Tetzlaff et al (64) analyzed global miRNA expression profiles through microarray chips in a series of samples of
PTC in formalin-fixed paraffin-embedded tissue (FFPE) and compared them to the expression profiles of benign proliferative multinodular goiter (MNG). The analysis revealed a series of 13 miRNAs upregulated and a series of 26 miRNAs downregulated. The validation by RT-PCR, in an independent set of tumor tissues, was performed only for miR-21, miR-31, miR-221 and miR-222. miR-221 and miR-222 were upregulated in PTC compared to the MNG group. The authors highlighted their ability to procure sufficient miRNA from FFPE tissue to describe a series of miRNAs with deregulated expression, demonstrating that FFPE tissues are suitable resources for such miRNA expression analyses when fresh tissues are not available or for performing retrospective studies.

Chen et al (65) analyzed the expression of a selected group of miRNAs. The results showed that miR-146b was consistently overexpressed in both classical papillary carcinoma and follicular variants, whereas all other groups displayed lower expression at a similar level. Follicular lesions with partial features of papillary carcinoma all showed low miR-146b levels similar to other non-papillary carcinoma groups, suggesting that they are biologically distinct from papillary carcinoma. miR-221 and miR-222 also showed a higher expression in papillary carcinoma, but with substantial overlaps between the other groups blocking their use as biomarkers for PTC lesions. When these analyses were applied to 40 FNA samples of various lesions, only miR-146b and miR-222 persisted as distinguishing markers for papillary carcinoma. They concluded that miRNAs, particularly miR-146b, may potentially be adjunct markers for diagnosing PTC in both FNA and surgical pathology specimens. Moreover they found that the overexpression of miR-146b is common both in classic and follicular variants of PTC, regardless of the BRAF mutation status.

The effect of BRAF mutations on miRNA expression profiles in PTCs has also been analyzed by Sheu et al (66). Differences were not recognized in the expression profiles of 5 miRNAs (miR-21, miR-146b, miR-181b miR-221 and miR-222) between PTCs with BRAF V600E mutation and wild-type PTCs.

Recently, Sheu et al (67) explored whether miRNA upregulation could be assigned to distinct histomorphological variants of PTC, particularly the follicular variant and other encapsulated follicular thyroid tumors. The authors concluded that the analysis of a set of 5 selected miRNAs distinguished common variants of PTC from FA/MNG but failed to be a useful diagnostic method in individual and doubtful cases, especially in the differential diagnosis of encapsulated follicular thyroid tumors.

In another study, Sheu et al (68) compared the expression patterns of miRNAs (-146b, -181b, -21, -221, -222), in PTC and in hyalinizing trabecular thyroid tumors (HTTs). Moreover, the 2 common genetic alterations characteristic of PTC, the V600E mutation of BRAF gene and the rearrangements of RET/PTC 1 and 3, were determined in all HTTs. All miRNAs were significantly upregulated in PTC, while all miRNAs in HTT, normal thyroid tissue, adenomas and MNGs were downregulated. All HTTs lacked BRAF mutations and RET/PTC rearrangements. These results did not support the concept that a high proportion of HTTs represents a variant of PTC and the authors suggested that HTTs lacking both a miRNA expression pattern characteristic of PTC and RET/PTC rearrangements be re-designated as 'hyalinizing trabecular adenomas'. 
Chou et al (69) evaluated the expression of miR-146b, miR-221 and miR-222 in 100 cases of PTC, with distinct clinicopathogenetic characteristics, and 16 paired normal controls. The tumor samples were categorized into low- and high-risk groups on the basis of the tumor-node-metastasis staging system. miR-221, miR-222 and miR-146b were significantly associated with extrathyroidal invasion and the expression levels of miR-221 and miR-146b were significantly higher in the high-risk PTC group. The miR-146b expression levels in PTCs with BRAF mutation were significantly higher than those without this mutation.

Visone et al (70), after identifying the upregulation of miR-221 and miR-222 in human thyroid papillary carcinomas, searched for their molecular targets. Through a bioinformatic approach, it was reported that the gene, CDKN1B (p27kip1, protein name), an important regulator of the cell cycle able to inhibit the initiation of th S phase, was the candidate target of the miR-221/222 cluster. They reported that an enforced expression of the miR-221 and miR-222 induced the thyroid papillary carcinoma cell line (TPC-1) to progress to the the $S$ phase of the cell cycle. Moreover, the negative regulation of p27(Kip1) by miR-221 and miR-222 may also play a role in vivo since an inverse correlation between miR-221 and miR-222 upregulation and downregulation of the p27(Kip1) protein levels in human thyroid papillary carcinomas was reported. By contrast, inhibition of the expression of miR-221 and miR-222 through specific antisense oligonucleotides 2'-OMe-221 and 2'-O-Me-222 increased the p27(Kip1) protein levels. As the authors proposed, these results strongly suggest the involvement of miR-221 and miR-222 in the cell cycle control through the modification of the p27(Kip1) protein level in the cell.

Anaplastic thyroid carcinoma. ATCs are highly aggressive and fatal tumors with a mean survival of less than 8 months after diagnosis (71). Various treatment patterns including radiation and chemotherapy have been used in ATC, but they are mostly unsuccessful (72). Therefore, the identification of miRNAs involved in proliferation or apoptosis in ATC cells has important therapeutic implications and may lead to the establishment of a novel therapy for ATC.

Takakura et al (73) investigated the role of those miRNAs specifically deregulated in ATC focusing on the miR-17-92 cluster, composed of 7 miRNAs (miR-17-5p, miR-17-3p, miR-18a, miR-19a, miR-20a, miR-19b and miR-92-1). They first assessed the overexpression of the miR-17-92 cluster in different ATC cell lines and then investigated the functional role of these miRNAs through cell transfection with miRNA inhibitors. The suppression of miR-17-3p caused complete growth arrest, presumably due to caspase- 3 and -9 activation, resulting in apoptosis. The miR-17-5p or miR-19a inhibitor also induced strong growth reduction, but only the miR-17-5p inhibitor led to cellular senescence. The miR-17-5p and miR-19a targets were identified in the RB1 and PTEN genes as their expression increased after transfection with the miR17-5p and miR-19a inhibitors.

It is becoming clear that PTEN plays a crucial role in thyroid cancer. Germinal mutations are associated with Cowden's syndrome and the reduced expression of PTEN plays a crucial role in thyroid cancer (74). Moreover, it has been reported that
PTEN inactivation is involved in highly malignant or latestage thyroid cancer, especially in the anaplastic subtype (75). Therefore, the overexpression of miR-19a and miR-19b may be associated with the translational suppression of PTEN and the induced cell growth in ATC (73). By contrast, miR-18a inhibitor only moderately attenuated cell growth. As proposed by the authors, these inhibitors may represent valid therapeutic approaches for the treatment of ATC.

Mitomo et al (76) examined miRNA expression in ATC, PTC cell lines and ATC, PTC tissue samples. They quantitatively evaluated the expression of multiple miRNAs, 5 upregulated and 5 downregulated miRNAs previously reported to be differentially expressed in comparison to normal thyroid tissues $(61,66)$. miR-138 was the only one significantly downregulated in ATC cell lines in comparison to PTC cell lines. Then, they searched for target genes of miR-138 using the miRBase and among 793 target genes they focused on the hTERT (human telomerase reverse transcriptase gene) gene as the overexpression of its protein has been reported in primary ATC in comparison with PTC (77). They demonstrated that the overexpression of miR-138 induced a reduction in hTERT protein expression, and confirmed target specificity between miR-138 and the hTERT 3'-untranslated region. These results suggest that the loss of miR-138 expression may partially contribute to the gain of hTERT protein expression in ATC, and that further multiple miRNAs targeting hTERT mRNA may be involved in the development of thyroid carcinoma. As proposed by the authors, the upregulation of hTERT, subsequent to the downregulation of miR-138, may be responsible for the malignant progression of well-differentiated PTC in more aggressive ATC (77).

In 2010, Braun et al (78) identified 2 significantly decreased miRNA families that unambiguously distinguish ATCs from PTCs and FTCs: miR-200 and miR-30. The expression of these miRNAs in mesenchymal ATC-derived cells reduced their invasive potential and induced mesenchymal-epithelial transition (MET) by regulating the expression of MET marker proteins. Supporting the role of TGF- $\beta$ signaling in modulating MET/epithelial-mesenchymal transition (EMT), the expression of SMAD2 and TGF- $\beta$ R1, upregulated in most primary ATCs, was controlled by members of the miR-30 and/or miR-200 families in ATC-derived cells. These findings identify altered miRNA signatures as potent markers for ATCs that promote de-/transdifferentiation (EMT) and invasion of these neoplasias. Hence, TGFBR1 inhibition may have significant potential for the treatment of ATCs and possibly other invasive tumors. The role of the miR-200 family has been previously shown in 60 different human cell lines as a regulator of the E-cadherinvimentin system (79).

Visone et al (80) analyzed miRNA expression profiles in ATC samples compared to normal thyroid tissues and found a significant downregulation of miR-26a, miR-30a-5p, miR-30d and miR-125b in ATC compared to normal samples. They found an aberrant miR expression profile that clearly differentiates ATC from normal thyroid tissues and from PTCs previously analyzed. The induced overexpression of miR-26a and miR-125b in 2 human ATC cell lines caused the inhibition of cell growth, suggesting a role of these 2 miRNAs in the negative regulation of the cell cycle and their downregulation in thyroid tumorigenesis. miR-26a influenced the progression 
of the cell cycle by adjusting the negatively EZH2 oncogene expression, a gene involved in the epigenetic silencing neoplastic development. Conversely, an effect on cell growth was not observed after the overexpression of miR-30d and miR-30a-5p in the same cells. These data indicate a miRNA signature associated with ATC and suggest the miR deregulation as an important event in thyroid cell transformation.

Pacifico et al (81) showed that NF- $\mathrm{B}$ contributes to anaplastic thyroid cancer by upregulating the expression of miR-146a. Since the regulation of miRNA expression is controlled by the RNA polymerase II-dependent transcription factors, NF- $\kappa$ B in the ATC-derived FRO cell line was inactivated and its miRNA profile in comparison with the parental counterpart was analyzed. miR-146a resulted in the overexpression of human ATC specimens compared with normal thyroid tissue. Moreover, the inhibition of miR-146a expression in FRO cells decreased their oncogenic potential and increased the susceptibility of the cells to chemotherapeutic drug-induced apoptosis. The authors suggested that NF- $\kappa \mathrm{B}$ contributes to anaplastic thyroid cancer by upregulating the expression of miR-146a.

Medullary thyroid carcinoma. Only 2 studies have analyzed the expression profile of miRNAs in MTC.

Nikiforova et al (51) analyzed the expression of miRNAs in surgically removed thyroid neoplastic and non-neoplastic samples and in FNA samples, finding a group of 10 specific miRNAs (miR-9, miR-10a, miR-124a, miR-127, miR-129, miR-137, miR -154, miR-224, miR-323 and miR-370) upregulated in MTC.

In 2011, Abraham et al (82) analyzed miRNA expression in order to identify potential prognostic biomarkers and therapeutic targets in MTC management. miRNA microarray profiling was carried out on tissue samples from patients with sporadic medullary thyroid cancer (SMTC) and hereditary medullary thyroid cancer (HMTC). The functional role of a selected miRNA was also investigated in vitro in the human MTC cell line (TT cells). miRs-183 and -375 were overexpressed and miR-9 was underexpressed in SMTC vs. HMTC. The overexpression of miRs-183 and -375 in MTC predicted lateral lymph node metastases and was also associated with residual disease, distant metastases and mortality. Knockdown of miR-183 expression in the TT cell line induced a significant decrease in the viable cell count and upregulation of the LC3B protein, which is associated with autophagy. This study indicated that miRNAs may play a pivotal role in the biology of MTC and represent an important class of prognostic biomarkers and therapeutic targets warranting further investigation.

\section{Conclusion}

miRNAs mediate a recently recognized form of translational inhibition that alters the levels of critical proteins, thereby providing a mechanism for spatiotemporal control of developmental and homeostatic events across a wide range of plants and animals $(4,85)$. Since abnormal proliferation and apoptosis are a hallmark of human cancers, it is possible that miRNA expression patterns may denote the malignant state. The altered expression of a few miRNAs has been found in some tumor types, and previous studies have shown that the altered expres- sion of specific miRNA genes contributes to the initiation and progression of cancer $(1,5,16,34,38,39,43,83-87)$. Therefore, miRNA expression profiles offer the potential to inform cancer classification, diagnosis and prognosis.

Thyroid cancers comprise a broad spectrum of lesions with different degrees of malignancy representing a useful model to study miRNA expression profiles. Several studies have demonstrated that various histopathological types of thyroid tumor, derived from the same cell, have distinct miRNA profiles, which further differ within the same tumor type reflecting specific oncogenic mutations in these tumors. These insights have an important implication on the classification of thyroid tumors and refine their scheme of progression. One of the main diagnostic problems in thyroid cancers involves the preoperative assessment of thyroid nodules. Thyroid FNA is an important method for the pre-operative evaluation of thyroid nodules, although in 10-20\% of samples, the a diagnosis cannot be reached (88). Therefore, additional methods to improve the pre-operative diagnosis are highly desirable and would result in a major impact on clinical assistance. A recent study reported the possibility of using circulating miRNAs (plasma, serum, urine or other bodily fluids) as a new class of biomarkers for the diagnosis of cancer as the expression profiles of miRNAs are specifically associated with certain types of cancer (89).

\section{References}

1. Meltzer PS: Cancer genomics: small RNAs with big impacts. Nature 435: 745-746, 2005.

2. He L and Hannon GJ: MicroRNAs: small RNAs with a big role in gene regulation. Nat Rev Genet 5: 522-531, 2004.

3. Bentwich I, Avniel A, Karov Y, Aharonov R, Gilad S, Barad O, Barzilai A, Einat P, Einav U, Meiri E, et al: Identification of hundreds of conserved and nonconserved human microRNAs. Nat Genet 37: 766-770, 2005.

4. Bartel DP: MicroRNAs: target recognition and regulatory functions. Cell 136: 215-233, 2009.

5. McManus MT: MicroRNAs and cancer. Semin Cancer Biol 13: 253-258, 2003

6. Croce CM and Calin GA: miRNAs, cancer, and stem cell division. Cell 122: 6-7, 2005.

7. Sevignani C, Calin GA, Siracusa LD and Croce CM: Mammalian micro-RNAs: a small world for fine-tuning gene expression. Mamm Genome 17: 189-202, 2006.

8. Calin GA and Croce CM: MicroRNA-cancer connection: the beginning of a new tale. Cancer Res 66: 7390-7394, 2006.

9. Chan JA, Krichevsky AM and Kosik KS: MicroRNA-21 is an antiapoptotic factor in human glioblastoma cells. Cancer Res 65 : 6029-6033, 2005.

10. DeLellis RA, Lloyd RV, Heitz PU and Eng C (eds): World Health Organization Classification of Tumors. Pathology and Genetics of Tumors of Endocrine Organs. IARC Press, Lyon, 2004.

11. Wightman B, Ha I and Ruvkun G: Posttranscriptional regulation of the heterochronic gene lin-14 by lin- 4 mediates temporal pattern formation in C.elegans. Cell 75: 855-862, 1993.

12. Lee RC, Feinbaum RL and Ambros V: The C. elegans heterochronic gene lin- 4 encodes small RNAs with antisense complementarity to lin-14. Cell 75: 843-854, 1993.

13. Reinhart BJ, Slack FJ, Basson M, Pasquinelli AE, Bettinger JC, Rougvie AE, Horvitz HR and Ruvkun G: The 21-nucleotide let-7 RNA regulates developmental timing in Caenorhabditis elegans. Nature 403: 901-906, 2000.

14. Pasquinelli AE, Reinhart BJ, Slack F, Martindale MQ, Kuroda MI, Maller B, Hayward DC, Ball EE, Degnan B, Müller P, et al: Conservation of the sequence and temporal expression of let-7 heterochronic regulatory RNA. Nature 408: 86-89, 2000.

15. Lee RC and Ambros V: An extensive class of small RNAs in Caenorhabditis elegans. Science 294: 862-864, 2001.

16. Lagos-Quintana M, Rauhut R, Lendeckel W and Tuschl T: Identification of novel genes coding for small expressed RNAs. Science 294: 853-858, 2001. 
17. Lau NC, Lim LP, Weinstein EG and Bartel DP: An abundant class of tiny RNAs with probable regulatory roles in Caenorhabditis elegans. Science 294: 858-862, 2001.

18. Xie X, Lu J, Kulbokas EJ, Golub TR, Mootha V, Lindblad-Toh K, Lander ES and Kellis M: Systematic discovery of regulatory motifs in human promoters and 30 UTRs by comparison of several mammals. Nature 434: 338-345, 2005.

19. Bartel DP: MicroRNAs: genomics, biogenesis, mechanism and function. Cell 116: 281-297, 2004.

20. Kim VN and Nam JW: Genomics of microRNA. Trends Genet 22: 165-173, 2006.

21. Han J, Lee Y, Yeom KH, Nam JW, Heo I, Rhee JK, Sohn SY, Cho Y, Zhang BT and Kim VN: Molecular basis for the recognition of primary microRNAs by the Drosha-DGCR8 complex. Cell 125: 887-901, 2006.

22. Lee Y, Jeon K, Lee JT, Kim S and Kim VN: MicroRNA maturation: stepwise processing and subcellular localization. EMBO J 21: 4663-4670, 2002.

23. Lee Y, Ahn C, Han J, Choi H, Kim J, Yim J, Lee J, Provost P, Radmark O, Kim S and Kim VN: The nuclear RNase III Drosha initiates microRNA processing. Nature 425: 415-419, 2003.

24. Lund E, Guttinger S, Calado A, Dahlberg JE and Kutay U: Nuclear export of microRNA precursors. Science 303: 95-98, 2004.

25. Yi R, Qin Y, Macara IG and Cullen BR: Exportin-5 mediates the nuclear export of pre-microRNAs and short hairpin RNAs. Genes Dev 17: 3011-3016, 2003.

26. Bohnsack MT, Czaplinski K and Gorlich D: Exportin 5 is a RanGTP-dependent dsRNA-binding protein that mediates nuclear export of premiRNAs. RNA 10: 185-191, 2004.

27. Chendrimada TP, Gregory RI, Kumaraswamy E, Norman J, Cooch N, Nishikura K and Shiekhattar R: TRBP recruits the Dicer complex to Ago2 for microRNA processing and gene silencing. Nature 436: 740-744, 2005.

28. Gregory RI, Chendrimada TP, Cooch N and Shiekhattar R Human RISC couples microRNA biogenesis and post-transcriptional gene silencing. Cell 123: 631-640, 2005.

29. Meister G, Landthaler M, Patkaniowska A, Dorsett Y, Teng G and Tuschl T: Human Argonaute2 mediates RNA cleavage targeted by miRNAs and siRNAs. Mol Cell 15: 185-197, 2004.

30. Hammond SC, Bernstein E, Beach D and Hannon GJ: An RNA-directed nuclease mediates post-transcriptional gene silencing in Drosophila cells. Nature 404: 293-296, 2000.

31. Zeng Y, Wagner EJ and Cullen BR: Both natural and designed micro RNAs can inhibit the expression of cognate mRNAs when expressed in human cells. Mol Cell 9: 1327-1333, 2002.

32. Zeng Y and Cullen BR: Sequence requirements for microRNA processing and function in human cells. RNA 9: 112-123, 2003.

33. Esquela-Kerscher A and Slack FJ: Oncomirs - microRNAs with a role in cancer. Nat Rev 6: 259-269, 2006.

34. Calin GA, Sevignani C, Dumitru CD, Hyslop T, Noch E, Yendamuri S, Shimizu M, Rattan S, Bullrich F, Negrini M and Croce CM: Human microRNA genes are frequently located at fragile sites and genomic regions involved in cancers. Proc Natl Acad Sci USA 101: 2999-3004, 2004.

35. Lu J, Getz G, Miska EA, Alvarez-Saavedra E, Lamb J, Peck D, Sweet-Cordero A, Ebert BL, Mak RH, Ferrando AA, et al: MicroRNA expression profiles classify human cancers. Nature 435: 834-838, 2005

36. Lewis BP, Shih IH, Jones-Rhoades MW, Bartel DP and Burge CB: Prediction of mammalian microRNA targets. Cell 115: 787-798, 2003.

37. Hammond SM: MicroRNAs as oncogenes. Curr Opin Genet Dev 16: 4-9, 2006.

38. Johnson SM, Grosshans H, Shingara J, Byrom M, Jarvis R, Cheng A, Labourier E, Reinert KL, Brown D and Slack FJ: RAS is regulated by the let-7 microRNA family. Cell 120: 635-647, 2005

39. Calin GA, Liu CG, Sevignani C, Ferracin M, Felli N, Dumitru CD, Shimizu M, Cimmino A, Zupo S and Dono M: MicroRNA profiling reveals distinct signatures in B cell chronic lymphocytic leukemias. Proc Natl Acad Sci USA 101: 11755-11760, 2004.

40. He L, Thomson JM, Hemann MT, Hernando-Monge E, Mu D Goodson S, Powers S, Cordon-Cardo C, Lowe SW, Hannon GJ and Hammond SM: A microRNA polycistron as a potential human oncogene. Nature 435: 828-833, 2005.

41. Yanaihara N, Caplen N, Bowman E, Seike M, Kumamoto K, Yi M, Stephens RM, Okamoto A, Yokota J, Tanaka T, et al: Unique microRNA molecular profiles in lung cancer diagnosis and prognosis. Cancer Cell 9: 189-198, 2006.
42. Cimmino A, Calin GA, Fabbri M, Iorio MV, Ferracin M, Shimizu M, Wojcik SE, Aqeilan RI, Zupo S, Dono M, et al: miR-15 and miR-16 induce apoptosis by targeting BCL2. Proc Natl Acad Sci USA 102: 13944-13949, 2005.

43. Iorio MV, Ferracin M, Liu CG, Veronese A, Spizzo R, Sabbioni S, Magri E, Pedriali M, Fabbri M, Campiglio M, et al: MicroRNA gene expression deregulation in human breast cancer. Cancer Res 65: 7065-7070, 2005

44. Felli N, Fontana L, Pelosi E, Botta R, Bonci D, Facchiano F, Liuzzi F, Lulli V, Morsilli O, Santoro S, et al: Micro-RNAs 221 and 222 inhibit normal erythropoiesis and erythroleukemic cell growth via kit receptor down-modulation. Proc Natl Acad Sci USA 102: 18081-18086, 2005

45. Volinia S, Calin GA, Liu CG, Ambs S, Cimmino A, Petrocca F, Visone R, Iorio M, Roldo C, Ferracin M, et al: A microRNA expression signature of human solid tumors defines cancer gene targets. Proc Natl Acad Sci USA 103: 2257-2261, 2006.

46. Voorhoeve PM, le Sage C, Schrier M, Gillis AJ, Stoop H, Nagel R, Liu YP, van Duijse J, Drost J, Griekspoor A, et al: A genetic screen implicates miRNA-372 and miRNA-373 as oncogenes in testicular germ cell tumors. Cell 124: 1169-1181, 2006.

47. Weber F, Teresi RE, Broelsch CE, Frilling A and Eng C: A limited set of human MicroRNA is deregulated in follicular thyroid carcinoma. J Clin Endocrinol Metab 91: 3584-3591, 2006.

48. Argraves WS, Greene LM, Cooley MA and Gallagher WM: Fibulins: physiological and disease perspectives. EMBO Rep 4: 1127-1131, 2003

49. Gallagher WM, Greene LM, Ryan MP, Sierra V, Berger A, Laurent-Puig P and Conseiller E: Human fibulin-4: analysis of its biosynthetic processing and mRNA expression in normal and tumour tissues. FEBS Lett 489: 59-66, 2001.

50. Schulte KM, Jonas C, Krebs R and Röher HD: Activin A and activin receptors in thyroid cancer. Thyroid 11: 3-14, 2001.

51. Nikiforova MN, Tseng GC, Steward D, Diorio D and Nikiforov YE: MicroRNA expression profiling of thyroid tumors: biological significance and diagnostic utility. J Clin Endocrinol Metab 93: 1600-1608, 2008.

52. Colamaio M, Borbone E, Russo L, Bianco M, Federico A, Califano D, Chiappetta G, Pallante P, Troncone G, Battista S and Fusco A: miR-191 down-regulation plays a role in thyroid follicular tumors through CDK6 targeting. J Clin Endocrinol Metab 96: 1915-1924, 2011.

53. Jemal A, Clegg LX, Ward E, Ries LA, Wu X, Jamison PM, Wingo PA, Howe HL, Anderson RN and Edwards BK: Annual report to the nation on the status of cancer, 1975-2001, with a special feature regarding survival. Cancer 101: 3-27, 2004.

54. Kimura ET, Nikiforova MN, Zhu Z, Knauf JA, Nikiforov YE and Fagin JA: High prevalence of BRAF mutations in thyroid cancer: genetic evidence for constitutive activation of the RET/PTC-RAS-BRAF signaling pathway in papillary thyroid carcinoma. Cancer Res 63: 1454-1457, 2003.

55. Melillo RM, Castellone MD, Guarino V, De Falco V, Cirafici AM, Salvatore G, Caiazzo F, Basolo F, Giannini R, Kruhoffer M, et al: The RET/PTC-RAS-BRAF linear signaling cascade mediates the motile and mitogenic phenotype of thyroid cancer cells. J Clin Invest 115: 1068-1081, 2005.

56. Cohen Y, Xing M, Mambo E, Guo Z, Wu G, Trink B, Beller U, Westra WH, Ladenson PW and Sidransky D: BRAF mutation in papillary thyroid carcinoma. J Natl Cancer Inst 95: 625-627, 2003.

57. Nikiforova MN, Kimura ET, Gandhi M, Biddinger PW, Knauf JA, Basolo F, Zhu Z, Giannini R, Salvatore G, Fusco A, et al: BRAF mutations in thyroid tumors are restricted to papillary carcinomas and anaplastic or poorly differentiated carcinomas arising from papillary carcinomas. J Clin Endocrinol Metab 88: 5399-5404, 2003.

58. Czene K, Lichtenstein P and Hemminki K: Environmental and heritable causes of cancer among 9.6 million individuals in the Swedish Family-Cancer Database. Int J Cancer 99: 260-266, 2002.

59. He H, Jazdzewski K, Li W, Liyanarachchi S, Nagy R, Volinia S, Calin GA, Liu CG, Franssila K, Suster S, et al: The role of microRNA genes in papillary thyroid carcinoma. Proc Natl Acad Sci USA 102: 19075-19080, 2005.

60. Cahill S, Smyth P, Finn SP, Denning K, Flavin R, O'Regan EM, Li J, Potratz A, Guenther SM, Henfrey R, et al: Effect of ret/ PTC 1 rearrangement on transcription and post-transcriptional regulation in a papillary thyroid carcinoma model. Mol Cancer 5: 70,2006 
61. Ricarte-Filho JC, Fuziwara CS, Yamashita AS, Rezende E da-Silva MJ and Kimura ET: Effects of let-7 microRNA on cell growth and differentiation of papillary thyroid cancer. Transl Oncol 2: 236-241, 2009

62. Pallante P, Visone R, Ferracin M, Ferraro A, Berlingieri MT, Troncone G, Chiappetta G, Liu CG, Santoro M, Negrini M, et al: MicroRNA deregulation in human thyroid papillary carcinomas. Endocr Relat Cancer 13: 497-508, 2006.

63. Chiang HR, Schoenfeld LW, Ruby JG, Auyeung VC, Spies N, Baek D, Johnston WK, Russ C, Luo S, Babiarz JE, et al Mammalian microRNAs: experimental evaluation of novel and previously annotated genes. Genes Dev 24: 992-1009, 2010.

64. Tetzlaff MT, Liu A, Xu X, Master SR, Baldwin DA, Tobias JW, Livolsi VA and Baloch ZW: Differential expression of miRNAs in papillary thyroid carcinoma compared to multinodular goiter using formalin fixed paraffin embedded tissues. Endocr Pathol 18: 163-173, 2007.

65. Chen YT, Kitabayashi N, Zhou XK, Fahey TJ III and Scognamiglio T: MicroRNA analysis as a potential diagnostic tool for papillary thyroid carcinoma. Mod Pathol 21: 1139-1146, 2008.

66. Sheu SY, Grabellus F, Schwertheim S, Handke S, Worm K and Schmid KW: Lack of correlation between BRAF V600E mutational status and the expression profile of a distinct set of miRNAs in papillary thyroid carcinoma. Horm Metab Res 41 482-487, 2009.

67. Sheu SY, Grabellus F, Schwertheim S, Worm K, BroeckerPreuss M and Schmid KW: Differential miRNA expression profiles in variants of papillary thyroid carcinoma and encapsulated follicular thyroid tumours. Br J Cancer 102: 376-382, 2010

68. Sheu SY, Vogel E, Worm K, Grabellus F, Schwertheim S and Schmid KW: Hyalinizing trabecular tumour of the thyroiddifferential expression of distinct miRNAs compared with papillary thyroid carcinoma. Histopathology 56: 632-640, 2010.

69. Chou CK, Chen RF, Chou FF, Chang HW, Chen YJ, Lee YF, Yang KD, Cheng JT, Huang CC and Liu RT: miR-146b is highly expressed in adult papillary thyroid carcinomas with high risk features including extrathyroidal invasion and the BRAF mutation. Thyroid 20: 489-494, 2010.

70. Visone R, Russo L, Pallante P, De Martino I, Ferraro A, Leone V, Borbone E, Petrocca F, Alder H, Croce CM and Fusco A: MicroRNAs (miR)-221 and miR-222, both overexpressed in human thyroid papillary carcinomas, regulate p27 protein levels and cell cycle. Endocr Relat Cancer 14: 791-798, 2007.

71. Ain KB: Anaplastic thyroid carcinoma: behavior, biology, and therapeutic approaches. Thyroid 8: 715-722, 1998.

72. Vini L and Harmer C: Management of thyroid cancer. Lancet Oncol 3: 407-414, 2002

73. Takakura S, Mitsutake N, Nakashima M, Namba H, Saenko VA, Rogounovitch TI, Nakazawa Y, Hayashi T, Ohtsuru A and Yamashita S: Oncogenic role of miR-17-92 cluster in anaplastic thyroid cancer cells. Cancer Sci 99: 1147-1154, 2008.

74. Bruni P, Boccia A, Baldassarre G, Trapasso F, Santoro M, Chiappetta G, Fusco A and Viglietto G: PTEN expression is reduced in a subset of sporadic thyroid carcinomas: evidence that PTEN-growth suppressing activity in thyroid cancer cells is mediated by p27kip1. Oncogene 19: 3146-3155, 2000.

75. Frisk T, Foukakis T, Dwight T, Lundberg J, Höög A, Wallin G, Eng C, Zedenius J and Larsson C: Silencing of the PTEN tumor-suppressor gene in anaplastic thyroid cancer. Genes Chromosomes Cancer 35: 74-80, 2002.
76. Mitomo S, Maesawa C, Ogasawara S, Iwaya T, Shibazaki M, Yashima-Abo A, Kotani K, Oikawa H, Sakurai E, Izutsu N, et al: Downregulation of miR-138 is associated with overexpression of human telomerase reverse transcriptase protein in human anaplastic thyroid carcinoma cell lines. Cancer Science 99: 280-286, 2008

77. Ito Y, Yoshida H, Tomoda C, Uruno T, Takamura Y, Miya A, Kobayashi K, Matsuzuka F, Kuma K and Miyauchi A: Telomerase activity in thyroid neoplasms evaluated by the expression of human telomerase reverse transcriptase (hTERT). Anticancer Res 25: 509-514, 2005.

78. Braun J,Hoang-Vu C, Dralle H and Hüttelmaier S: Downregulation of microRNAs directs the EMT and invasive potential of anaplastic thyroid carcinomas. Oncogene 29: 4237-4244, 2010.

79. Park SM, Gaur AB, Lengyel E and Peter ME: The miR-200 family determines the epithelial phenotype of cancer cells by targeting the E-cadherin repressors ZEB1 and ZEB2. Gen Dev 22: 894-907, 2008.

80. Visone R, Pallante P, Vecchione A, Cirombella R, Ferracin M, Ferraro A, Volinia S, Coluzzi S, Leone V, Borbone E, et al: Specific microRNAs are downregulated in human thyroid anaplastic carcinomas. Oncogene 26: 7590-7595, 2007.

81. Pacifico F, Crescenzi E, Mellone S, Iannetti A, Porrino N, Liguoro D, Moscato F, Grieco M, Formisano S and Leonardi A: Nuclear factor- $\{$ kappa\}B contributes to anaplastic thyroid carcinomas through upregulation of miR-146a. J Clin Endocrinol Metab 95: 1421-1430, 2010.

82. Abraham D, Jackson N, Gundara JS, Zhao J, Gill AJ, Delbridge L, Robinson BG and Sidhu SB: MicroRNA profiling of sporadic and hereditary medullary thyroid cancer identifies predictors of nodal metastasis, prognosis, and potential therapeutic targets. Clin Cancer Res 17: 4772-4781, 2011.

83. Ambros V: The functions of animal microRNAs. Nature 431: 350-355, 2004

84. Calin GA, Ferracin M, Cimmino A, Di Leva G, Shimizu M, Wojcik SE, Iorio MV, Visone R, Sever NI, Fabbri M, et al: A microRNA signature associated with prognosis and progression in chronic lymphocytic leukemia. N Engl J Med 353: 1793-1801, 2005.

85. Michael MZ, O'Connor SM, Van Holst Pellekaan NG, Young GP and James RJ: Reduced accumulation of specific microRNAs in colorectal neoplasia. Mol Cancer Res 1: 882-891, 2003.

86. Takamizawa J, Konishi $\mathrm{H}$, Yanagisawa K, Tomida S, Osada H, Endoh H, Harano T, Yatabe Y, Nagino M, Nimura Y, et al: Reduced expression of the let-7 microRNAs in human lung cancers in association with shortened postoperative survival. Cancer Res 64: 3753-3756, 2004.

87. Boeri M, Verri C, Conte D, Roz L, Modena P, Facchinetti F, Calabrò E, Croce CM, Pastorino U and Sozzi G: MicroRNA signatures in tissues and plasma predict development and prognosis of computed tomography detected lung cancer. Proc Natl Acad Sci USA 108: 3713-3718, 2011.

88. Popoveniuc G and Jonklaas J: Thyroid nodules. Med Clin North Am 96: 329-349, 2012

89. Zen K and Zhang CY: Circulating microRNAs: a novel class of biomarkers to diagnose and monitor human cancers. Med Res Rev 32: 326-348, 2012. 